Fecha de recepción: diciembre 2017 Fecha de aceptación: marzo 2018 Versión final: julio 2019

\section{"Solo hay un camino entre la persona que eres y la que quieres ser". Análisis de un curso de imagen bajo la óptica de El baile de los solteros}

Lorena N. Schiava D’Albano*

\begin{abstract}
Resumen: En el presente artículo estudio, bajo la óptica del trabajo de Pierre Bourdieu "Los campesinos y su cuerpo", mi participación como alumna en un curso de Imagen Pública y Privada. A partir de los conceptos de Habitus y Hexis corporal analizo los conocimientos que se transmiten en el curso no solo como información especializada en el tema sino como un conocimiento que transforma a los alumnos. En primer lugar, describo el trabajo de Bourdieu. Luego describo las clases y su dinámica: mi experiencia como alumna en el centro, el curso y mis compañeros. Por último, explico, a partir de los conceptos de Bourdieu, cómo y por qué pueden pensarse las clases como un espacio donde, además de brindarnos información, se construyen nuevas aspiraciones y deseos. Donde nos enseñan a mirar a un otro, pero no de cualquier manera sino de una que es solidaria con un contexto social y cultural donde esa mirada cobra sentido.
\end{abstract}

Palabras clave: Habitus - Hexis corporal - asesoramiento de imagen - persona.

[Resúmenes en inglés y portugués en la página 86]

${ }^{(*)}$ Lorena Schiava D’ Albano es Licenciada en Relaciones Internacionales y Profesora Universitaria de la Universidad John F. Kennedy, y Magíster en Antropología Social del IDES/ IDAES/UNSAM. Estudia la relación entre objetos, estilos de vida y construcción de la identidad desde la perspectiva de la cultura material. Correo: lorescd@yahoo.com

\title{
Introducción
}

Pierre Bourdieu en su trabajo de campo en Bearne, explica por qué las expectativas de las mujeres campesinas cambiaron a partir de su contacto con la vida en la ciudad. Las mujeres, dirá, aspiran con fervor a la vida ciudadana. Para muchas personas esa "ciudad" es representada por los ideales de belleza que son consumidos a través de diferentes medios de comunicación, revistas o películas. Ese interés y atracción no se limita a un consumo pasivo: quieren quitar ese velo invisible para saber cómo y a través de qué objetos pueden convertirse en aquello que aspiran o admiran. Esta necesidad dio paso a la creación de numerosos espacios como talleres, seminarios y cursos donde se proponen diferentes estrategias de transformación para convertirse en esa persona que uno quiere ser. 
Elegir un estilo, qué ponerse a la mañana o cómo combinar los colores de un atuendo no es una cuestión trivial en la vida de muchas personas. Para éstas, la forma en la que se presentan en sociedad, cómo se visten y los modales que adquieren hablan tanto de quiénes son como del lugar que ocupan o quieren ocupar en ese medio.

En marzo de 2017, como parte de mi trabajo de campo en el marco de la maestría en Antropología Social del IDES/IDAES, decidí inscribirme como alumna en un curso anual cuyo título final era de "Asesora de Imagen Pública y Privada" en el Centro de Diplomacia (CD) con el fin de conocer un espacio de aprendizaje cuyos contenidos y objetivos me eran ajenos. Durante las clases, dictadas por profesores especialistas, se trasmitía además de los contenidos pertinentes, que podemos encontrar en páginas de Internet, una forma particular de ver, de observar a otros y por consiguiente de observarnos.

La lectura del trabajo de Bourdieu "El baile de los solteros", en particular el capítulo 4 "El campesino y su cuerpo", me permitió analizar y pensar los conocimientos que se transmitían en el curso no solo como conceptos e información que podían encontrarse en libros especializados en el tema, sino como un conocimiento que nos transforma a quienes participamos en dicho espacio, incidiendo sobre nuestras categorías de percepción y acción. En el presente trabajo intentaré mostrar cómo en este curso cada clase funcionaba como un espacio pedagógico que buscaba transmitir cómo modelar el cuerpo de un cliente al mismo tiempo que nos moldeaba a nosotros, los propios alumnos. Me pregunto ¿Cómo se da ese proceso de asimilación y transformación de las expectativas durante las clases? ¿Cómo se incorporan y se hacen cuerpo esos conocimientos?

En la primera parte del trabajo, "Entrando al Baile en Bearne", reseñaré los puntos principales del trabajo de Bourdieu, luego en "Entrando al Baile en Recoleta" describiré el curso y el espacio donde el mismo tenía lugar, así como también a mis compañeras. En la segunda parte, "Bailando en París", me centraré en trabajar sobre las clases y su dinámica en tanto en la tercera parte, "Entrenando la mirada de Bearne a Recoleta", analizaré a partir de la teoría de Bourdieu, en especial a partir de los conceptos de Habitus y Hexis Corporal, cómo las clases funcionaban como un espacio donde, además de aprender sobre imagen pública y privada, se construían nuevas aspiraciones, deseos y expectativas. Es por lo tanto un espacio donde nos enseñan a observar e interpretar a un otro, el cliente, pero no de cualquier manera sino una que era coherente con el Centro de Diplomacia y con un contexto social y cultural donde esa mirada cobra sentido.

"La imagen personal es mucho más amplia que el vestir, es el conjunto de rasgos físicos, los gestos y movimientos, el estilo de caminar, el tono de voz, la forma de mirar, etc." Apunte clase de Imagen Personal

\section{Entrando al baile en Bearne}

“¿No bailas? No, eso, para nosotros pertenece al pasado" le dirá un campesino a otro durante el baile de Navidad en Bearne. Esta situación será descripta etnográficamente por 
Pierre Bourdieu en su texto "El campesino y su cuerpo". No era un evento más, el baile era una de las pocas ocasiones institucionalizadas de encuentro entre los sexos. Será, por lo tanto, una ocasión privilegiada para aprender la raíz de las tensiones y conflictos que eran vividos como un drama en Bearne: el aumento del celibato masculino. Para explicar esta situación, e intentar comprenderla más allá de los datos estadísticos, Bourdieu va a centrarse en el cuerpo de aquellos que van al baile. Para este autor en las dimensiones de su conformación visible (volumen, talla, peso, etc.), es un producto social y por lo tanto expresa una relación con el mundo social y cuenta la trayectoria en el mismo.

En el baile algunos de los participantes se mantenían al borde de la pista como una masa oscura, esos, dirá, son los campesinos solteros ¿Por qué no bailan? ¿Por qué se quedan aislados observando? Para Bourdieu hay algo que media entre el individuo y la estructura y eso es el habitus, "se trata de aquellas disposiciones a actuar, percibir, valorar, sentir y pensar de una cierta manera... es pues la historia hecha cuerpo" (Gutiérrez, 2005:68). Este concepto, junto con el de hexis corporal, esa modalidad práctica del cuerpo y objeto primero de la percepción, le permitirán explicar las diferencias en los usos corporales de los solteros y de los habitantes de la ciudad y con ellas exponer las diferentes categorías de percepción y apreciación de cada uno. Punto central para entender el comportamiento de los campesinos.

Bourdieu muestra a través de la descripción etnográfica cómo el ciudadano construye una relación entre las técnicas del cuerpo y su correlación a nivel del significado a partir de los modos corporales del campesino, definido en eso que se llamaba el "aspecto campesino". Es el "habitus que deja al descubierto al paysanas, al campesino pesadote y torpón. La observación popular ha sabido captar a la perfección esa hexis en la que se basan los estereotipos" (Bourdieu, 1986: 112). Es decir, una hexis corporal cargada de significados y valores sociales, donde el campesino era percibido como torpe, poco sociable y hosco a partir de la observación de su cuerpo.

Bourdieu describe cómo los campesinos interiorizaban la percepción negativa de sí mismo que se formaban los demás. Esa imagen era lo que lo llevaba a sentirse incómodo en el baile, es decir con un cuerpo marcado por la impronta social. Es en la experiencia práctica, cotidiana, donde se refuerzan, actualizan y sostienen las representaciones sociales disponibles que también pueden tener un carácter creativo (Citro, 2010:220). El baile era un espacio donde los campesinos reforzaban y sostenían esa imagen de sí. Pero no todos, en una nota al pie el autor explica que muchos hombres que residían en el pueblo eran, objetivamente, tan paletos como algunos campesinos de los caseríos, pero no tenían conciencia de serlo, por eso sostiene que el campesino que tomaba conciencia de sí mismo tenía más posibilidades de concebirse como tal en el sentido peyorativo.

Esta mirada negativa sobre el campesino era también la de las mujeres, quienes los juzgaban aplicando criterios basados en los ideales ciudadanos que se construían a través de revistas femeninas, del cine, de las canciones de moda, etc. De esta manera, alejaban a los campesinos de la competencia en el mercado matrimonial. Para Bourdieu las mujeres eran más propensas a los ideales ciudadanos que conocían a partir de sus experiencias urbanas, de nuevas experiencias culturales, a través de las cuales asociaban la vida urbana con un determinado tipo de estética, copiaban de la ciudadana los signos externos de su condición, es decir, lo que sabían de ella. La ciudad representaba la esperanza de la eman- 
cipación. Las describirá peinadas y vestidas de manera elegante, todas con un aspecto de ciudadanas porque para ellas "la moda viene de París, de la ciudad; el modelo se impone desde arriba. Las mujeres aspiran con fervor a la vida ciudadana" (Bourdieu, 2004:120). ¿Cómo convertirse en ese modelo de mujer? ¿Cómo peinarse y vestirse como una mujer de ciudad? Estas preguntas también pueden pensarse para muchas personas que encuentran esa "ciudad" caracterizada por los ideales de belleza que son consumidos a través de diferentes medios. Pero ese interés y atracción no se limita a un consumo pasivo: quieren conocer cómo y a través de qué objetos pueden convertirse en aquello que aspiran o admiran. Esta necesidad explica, en parte, el surgimiento de espacios que buscan transmitir el conocimiento necesario para convertirse en la persona que uno quiere ser.

"tenemos que empezar a identificar no solo lo que vemos o leemos en la revista sino cuando vemos a un persona por la calle y decir esa persona lleva este tipo de zapato y entender por qué lo usa"

Comentario de Marcela durante la clase de accesorios

\section{Entrando al baile en Recoleta}

Inscribirse en un curso de Asesora de imagen implica asumir, por un lado, que hay personas que necesitan y quieren que una mirada experta les indique la forma "correcta" de vestirse y por otro que existen lugares donde se enseña la forma de lograrlo. No conocía sobre este tipo de cursos, para ser honesta, no sabía que existían. Pero a partir de recomendaciones en un taller de tesis y con la intención de explorar nuevos temas decidí anotarme en un curso de ceremonial y protocolo. Entre la gran cantidad de ofertas que encontré en Internet me llamo la atención uno en especial, el Centro de Diplomacia (CD), por la forma en la que el mismo se presentaba en la página de Internet. El curso tenía como objetivo darnos las herramientas necesarias para luego de 38 clases ser capaces de asesorar profesionalmente a un cliente, de manera que éste pueda construir y optimizar su imagen personal. El programa estaba organizado de forma tal que en cada una de las clases se proponía descomponer las partes que componían el estilo personal, desde la colorimetría pasando por formas de cuerpo, vestuario femenino y masculino, maquillaje, psicología de la personalidad, complementos y accesorios, hasta historia de la moda, entre otras. Las mismas eran dictadas por profesores especializados.

El centro estaba situado en el barrio de Recoleta, un barrio residencial con una carga simbólica de calidad y refinamiento, en un pasaje casi desapercibido cercano a una esquina. $\mathrm{Al}$ tocar la puerta 6 y luego de subir algunas escaleras me recibió Romina, secretaria y profesora de maquillaje del centro. Romina era una mujer delgada, de estatura media de unos 40 años, de pelo negro corto, bien peinada y maquillada. Estaba vestida de blanco con una musculosa con un delicado encaje en el frente y un pantalón de vestir blanco que, al ser delgada, le sentaba bien -según los cánones que se impartían en el curso-. Luego de presentarme y mientras pagaba la cuota correspondiente noté como, con sutileza, su mirada recorrió mi cuerpo y entendí que detrás de esa puerta la imagen era importante. 
Con voz suave y dulce me indicó el salón, el más grande de los dos que había, donde estaban esperando otras alumnas. Los colores grises y pasteles junto con la decoración daban la impresión de estar pensados, al igual que los cuadros con fotos de mujeres en blanco y negro expuestas como de una galería de arte. Dos grandes mesas con sillas, una al lado de la otra, marcaban el lugar donde nos sentábamos las alumnas, mientras que dos banquetas puestas enfrente, una con una computadora, señalaban el lugar de la profesora. Las luces estaban a media intensidad creando un espacio más íntimo, distante de un aula universitaria a la que estaba más acostumbrada. El salón estaba en silencio con pocos alumnos pero podía percibir el perfume de mis compañeros, algo que se volvería una rutina semanal. Luego de saludar a los presentes y mientras me sentaba, no podía dejar de pensar en cómo me había vestido ese día, un pantalón naranja con estrellas blancas, botas negras, una camisa blanca y un sweater gris, un peinado simple, mi pelo negro enrulado recogido en un rodete y sin maquillaje. Sentía la incomodad que no había experimentado en el tren desde mi casa, en la zona norte, camino al centro, pero el estar ahí entre mis compañeras, quienes en su mayoría estaban maquilladas, peinadas, vestidas y perfumadas para la ocasión, fui consciente de que mi imagen no era la adecuada. $\mathrm{Al}$ igual que el campesino, quien no estaba en su elemento durante el baile, supe que esta no era como el aula universitaria donde iba a estar cómoda. Los "bailes nuevos" a los que me iba a exponer durante un año me exigían la adopción de nuevos modos corporales. Soy de estatura baja, delgada y siempre tengo como primera opción un par de zapatillas y unos jeans que pensaba, hasta este día, combinaban con todo. Además, en mi círculo social no era un valor darle importancia a la vestimenta y menos invertir dinero en adquirir ropa u objetos caros y lujosos, pero formar parte de ese espacio implicaba cambiar mi visión.

Durante la primera clase me presenté al grupo, conformado por 18 mujeres y un varón, a quienes les expliqué mi intención principal: estaba ahí como estudiante de un posgrado en antropología, aunque también, agregué con intención de generar empatía, me generaba una gran curiosidad e interés el universo de la imagen personal al que sentía muy lejano. Nicolás era siempre el primero en llegar y elegía el lugar más cerca del profesor para sentarse. Tenía más de 30 años, su cabello era negro, corto y un tanto descuidado, generalmente usaba jeans combinado con remeras de colores oscuros, un estilo de vestir diferente al esperado en este tipo de espacios, lo cual me sorprendió mucho. Era de contextura corporal endomorfa, como aprendimos a decir. Estudió en la Escuela Argentina de Sommeliers, aunque le faltaban 6 materias para recibirse en ese momento; durante la semana trabajaba como técnico informático, razón por la que en una entrevista que le realicé antes de entrar a clases le era imposible asistir mejor vestido. Nicolás así reconocía que no tenía el aspecto esperado ni el que él deseaba tener. Era uno de los pocos junto con Cecilia, licenciada en marketing y madre de un hijo, que estudiaban asesoría de imagen como una salida laboral. Cecilia tenía 35 años, delgada, rubia de pelo lacio, un pelo que cuidaba como su cuerpo con buenos productos y tratamientos corporales en centros de estética. Durante varios años trabajó en un negocio de ropa en el sector de marketing lo que la llevó a conocer la moda y valorar estar siempre elegante.

La gran mayoría de mis compañeros cuyas edades oscilaban entre los 35 a los 60 años, algunos ya jubilados, explicaban como motivo principal de su participación, la calidez del CD y el reconocimiento que tenía Marcela, directora y profesora del CD, en el ámbito 
del protocolo y el ceremonial. Como Claudia, una señora de 56 años, quien reconocía que Marcela le había cambiado la vida en los cursos anteriores, en particular durante el curso de asesoramiento personalizado. Claudia era rubia, de pelo corto con rulos que siempre peinaba y cuidaba con las ampollas capilares que le habían recomendado según nos comentaba en las clases. Era de contextura delgada y tamaño petite algo que siempre resaltaba con humor; generalmente se la veía con pantalones de vestir oscuros que combinaba con diferentes camisas y pañuelos al cuello. Dada su estatura combinaba su look con zapatos de taco alto. A diferencia de otras compañeras, tenía un tono de voz más alto al hablar y sus modos no eran tan cuidados y medidos, le costaba caminar bien con tacos y no siempre sabía cómo combinar de manera apropiada la ropa, algo sobre lo que también bromeaba al reconocer que ella era 'un caso difícil'.

Cuando ya estábamos todos ubicados entró Marcela, una mujer de 43 años alta y de contextura delgada, rubia de pelo corto a la altura de los hombros, siempre peinada de peluquería y maquillada, de voz suave. Tenía un modo particular de hablar que al igual que su movimiento corporal era lento y medido, nunca brusco. Tenía un vestido corto, azul con flores en relieve, su pelo estaba recogido con un rodete tirante y stilettos del mismo color del vestido. Marcela transmitía seguridad en sus palabras, en su body language, y su ropa acompañaba esa imagen de mujer empresaria, resultado quizás de su formación de protocolo en la Protocol School en Washington, más los años de experiencia en asesoría pública y privada. Marcela sabía siempre desde dónde estaba hablando, a quiénes se estaba dirigiendo y lo que el grupo esperaba de ella. Desde hace más de 16 años se dedica a la asesoría de imagen personal y empresarial al mismo tiempo que trabajó en distintas universidades del país. Mientras duró el curso se desempeñaba como directora de Relaciones Institucionales de un importante instituto.

Los martes, como me fui dando cuenta clase a clase, no eran un día más en mi rutina semanal. Sabía que debía vestirme mejor para ir al curso donde todas mis compañeras iban a estar producidas para la ocasión, donde todas estarían atentas a cómo nos presentábamos. En una entrevista que le hice a mi compañera Pamela, madre de dos hijos ya mayores quien trabajaba como secretaria, me dirá "yo salgo a la mañana arreglada quiero llegar acá impecable pero ya llego así, destartalada la cara, igual trato de estar un poquito más arreglada los martes". Pamela es de estatura baja que lograba disimular con tacos, su pelo era castaño claro, lacio al que mantenía con productos capilares, generalmente usaba pantalones de vestir los que combinaba con camisas y un pañuelo de seda de colores que cuidadosamente acomodaba en el cuello. Sus modos eran suaves al igual que su voz, siempre estaba acompañada por Marianela con quien compartían trabajo y a quien logró entusiasmar para hacer el curso. Marianela tenía 28 años, estaba casada y a diferencia de Pamela era alta y delgada, rubia con el pelo largo debajo de los hombros. Solía ir a las clases con jeans y camisas. En la misma entrevista reconoció que "no me maquillo, nunca me maquillo, pero me maquillo los martes como para decir "mirá" y cuando llego a casa me pongo la jogineta y la remera".

Sabíamos que había algo especial y distinto en estos encuentros, el espacio, tanto del curso como del barrio donde el mismo se realizaba, nos interpelaba de una manera distinta, se esperaba algo de nosotras "las alumnas". Al igual que el campesino que describe Bourdieu que se siente torpe ante la presencia de los habitantes del pueblo, existía un reconocimien- 
to en algunos de alumnos de un malestar, de una incomodad al sentir que teníamos que vestirnos de manera distinta a la habitual. Esa incomodidad la reconocía en mí cada vez que me enfrentaba a mis compañeras, a sus tacos, su ropa de marca, sus carteras exclusivas, su maquillaje y sus perfumes importados. No estaba acostumbrada a darle un protagonismo a mi vestimenta ni importancia a los accesorios, con mi mochila negra donde me entraba todo me era suficiente o al menos eso creía. Era una distancia que se vivenciaba, que sentía y que no era salvada por el solo hecho de pensar con más cuidado sobre qué ponerme ese día. Había algo más que también nos diferenciaba: la forma de llevar la ropa, de caminar y de moverse, una hexis corporal distinta.

Pero también el encuentro de los alumnos y profesores en la clase genera algo. Nicolás en la misma entrevista me dirá "yo me pongo a pensar que estoy delante de alguien elegante, ¿y cómo me siento yo?, me siento como si al hablar con esa persona elegante ya parece que me elevo... o sea me transformo completamente y eso me doy cuenta acá mucho cuando hablo con Marcela... y bueno te realza" Ese "algo" que se generaba en los encuentros semanales, en este espacio compartido durante las clases era lo que motivaba a mis compañeros a seguir yendo, ese "algo" que no estaba en los libros, que no se podía encontrar en una página web.

En los apuntes de clase se definía al Asesor de Imagen como "un experto que cuenta con un profundo conocimiento de la construcción de la imagen personal. Posee herramientas necesarias para optimizar al cliente y además ha desarrollado un gran sentido de la estética” pero ¿era este el objetivo final de quienes estábamos ahí?

\section{Bailando en París}

"La imagen pública se sostiene todos los días de tu vida, no hay un solo día que te puedas relajar" nos dijo Marcela en la primera clase y con ello marcó el rumbo del curso. Estaba claro: la clave era la disciplina, la práctica y el control, a partir de lo aprendido en el curso, para poder ser nuestra mejor versión. Las clases no tenían un rigor académico: nunca comenzaban a horario, así las 19 hs. se transformaban en el horario de encuentro de puesta al día entre compañeros y momento privilegiado para intercambiar diferentes tips y recomendaciones entre las que se incluía información sobre los negocios que tenían liquidación y ofertas. El curso también funcionaba como un espacio de encuentro, de socialización, como en el caso de Cecilia, una abogada de 35 años, casada, quien había regresado hacía poco tiempo al país luego de residir varios años en el exterior. En una entrevista que le realicé me explicó que decidió inscribirse en el curso como un lugar donde encontrar y establecer nuevas amistades, además de querer aprender sobre imagen algo que también creía era importante para su profesión.

La presentación de cada clase, en general, estaba acompañada por videos seleccionados de marcas de indumentaria de lujo internacional o fotografías de actores y actrices de Hollywood que servían de disparador para introducir el tema y también como faro y parámetro de lo que se definía como la elegancia, imagen que encarnaba la actriz norteamericana Audrey Hepburn en particular en su papel de Holly Golightly en la película "Desayuno en Tiffany's" cuyo vestuario fue realizado por el modisto Hubert de Givenchy. Por lo tanto 
para ser elegante había que ser delgada, de estatura media, joven, vestida por ropa de diseñador, con un estilo sobrio, con los accesorios necesarios, de voz suave y movimientos sutiles. O por el contrario sancionar lo burdo, lo exagerado encarnado por la actriz argentina Moria Casán. Durante las mismas se hacía visible, tanto a través del discurso como de objetos que llevaban algunos profesores, el trabajo que se realizaba de construcción de un deseo y nuevas necesidades, "esta clase es aspiracional" sentenciará Marcela ante la atenta mirada del grupo.

Las clases nos exponían ante un mundo de experiencias, consumos y estilos de vida ajenos y distantes al de la mayoría de los alumnos. Durante el curso aprendíamos a reconocer perfumes y fragancias de 500 euros que se conseguían en pocas y exclusivas tiendas o proponer un viaje de compras a Dubai o en la clase de accesorios ver zapatos icónicos de 10.000 euros. ¿Por qué no generaba tensiones o malestar? ¿O al menos cuestionamientos? Muchas de mis compañeras sentían atracción y curiosidad por ese universo de consumo de lujos, querían saber qué famosa internacional o argentina podía comprarlo, dónde y cómo lo usaba. Querían quitar ese velo invisible y conocer ese detrás de escena, hacer ese viaje metafórico del campo a la ciudad, una ciudad que muchas reconocían estaba en París. Por momentos éramos esas campesinas que veían la ciudad en los grandes almacenes. Era interesante el discurso que se implementaba desde el centro donde, como se repetía en las clases, con tener dinero no es suficiente. Es decir, uno podía acceder a comprarse el pañuelo Hermés más caro pero si no sabía la forma apropiada de ponérselo o el modo correcto de combinarlo o el evento en el que mismo debía ser usado, el dinero no cumplía su función. Formar parte del curso nos daba la posibilidad, por lo tanto, de conocer y estar más cerca de aquello que se deseaba, al mismo tiempo que se construían nuevos deseos y aspiraciones.

Esperábamos que comenzara la clase sobre psicología de la moda cuando escuché a una de mis compañeras, Laura, comentar que había recibido un llamado donde le avisaban que ya estaba disponible "la negra 30". Fue inmediata la reacción de emoción de quienes estaban conversando con ella lo que me desconcertó aún más por no entender a qué se estaba haciendo referencia.

Laura era una mujer de más de 40 años con un estilo único y muy particular. Desde su color de pelo rubio, su corte que era obra de una peluquería en París durante su último viaje, su peinado que requería un trabajo y un cuidado especial que ella misma nos contaría, hasta el tipo de ropa que elegía ponerse nos remitía sin dudas a Marilyn Monroe, lo que hizo que desde el día que la conocimos todas nos referíamos a ella como "Marilyn" algo que le agradaba. Su presencia era deslumbrante, no sólo por su delgada figura que sabía resaltar con cortes de vestidos de estilo años 50, sino también por los accesorios con los que complementaba su look. Todas siempre esperábamos su llegada al centro para ver cómo estaba vestida, de qué diseñador eran sus zapatos, los que sabía lucir con un envidiable dominio y control, con qué cartera de marcas internacionales los iba a combinar, objetos en su mayoría adquiridos en sus frecuentes viajes a París. Su estilo único se completaba con un tono de voz suave, pausado y aniñado que le daban un aire de fragilidad.

Al ver que era una de las pocas que no entendía lo sucedido me decidí a preguntarle a la protagonista que le estaba por llegar, "la cartera Hermés" me respondió con una gran sonrisa. Una semana después del anuncio, llegó la cartera al curso y su presencia material 
revolucionó la clase, porque verla y tenerla frente a nosotros resultó toda una experiencia sensorial. Tal fue la reacción del grupo que muchas se congregaron alrededor de Laura, o mejor dicho de la cartera, para poder tenerla más cerca. Fue tal la atención que generó ese objeto negro y pequeño que terminó circulando de mano en mano para que todos tuviéramos la oportunidad de tocarla, olerla y observarla de manera más personal. De pronto me encontré con la cartera entre mis manos sin saber qué debía hacer, parecía una cartera más entre muchas, pero impulsada por el espíritu de la clase me dejé llevar por ese objeto y comencé a verlo de otra manera. Ya no era una cartera negra del montón, era la cartera Hermés.

Ese es el tipo de información, junto con una experiencia personal y material, que no estaba en los apuntes del curso pero que era conocido por quienes se acercan al centro. Un conocimiento que era compartido, entendido y valorado al mismo tiempo que podía hacerse gala del mismo como un bien preciado. Esto también era uno de los motivos que llevaban a este grupo de alumnos a inscribirse en el centro.

Durante las clases se repetía la consigna de estar atentas a la imagen que dábamos, de ser conscientes de lo que queríamos contar porque "la primera impresión social es la que cuenta". Así se reforzaba, sin decirlo, la idea de un otro que nos estaba viendo, pero un otro cuya mirada no era neutral, era una que nos estaba juzgando. Al mismo tiempo nosotros también éramos esa mirada que juzgaba, ahora impregnada de los conocimientos del curso: pasábamos así a ser también nuestros propios veedores. Interiorizábamos clase a clase esa mirada, esos valores, es decir ese nuevo marco de referencia. En mi caso comenzaban a cobrar importancia conocimientos que iba adquiriendo en las clases. Por ejemplo, luego de la clase de maquillaje incorporé la rutina de limpieza facial por las mañanas con sus tres pasos correspondientes, algo que desconocía y que recomendé a mis amigas.

Cada martes ser elegantes era un concepto que se repetía como un "mantra" y un norte a seguir por todos los profesores y que cruzaba todos los temas del curso. La elegancia para la gran mayoría de mis compañeras estaba relacionada con modos corporales, con la hexis, "es una forma de ser, una forma de caminar" me dirá Pamela en la entrevista. Era, como nos decían en el curso, una forma discreta, medida de mover las piernas manteniendo los brazos con movimientos sutiles, la mirada al frente, los hombros bajos con pisadas firmes que transmitan seguridad. Es decir, se hablaba de un cuerpo controlado, medido y pensado pero que con la práctica necesaria se convertiría en movimientos naturales, en un conocimiento incorporado, en una segunda piel. Al mismo tiempo la elegancia era definida en relación al gusto, algo que se entendía alejado del dinero, ser elegante era por lo tanto tener buen gusto al momento de vestirse, no bastaba con saber moverse con gracia: era necesario saber también qué usar y cómo usarlo. Como repetía Marcela había que entender la elegancia como una forma de vida, una elección.

Las clases así iban moldeando y dándole contenido a esa "ciudad" representada por los ideales estéticos de consumo y estilos de vida alimentada por imágenes de películas y de fotos de actores famosos que legitimaban ese deseo dándole forma a un relato que se hacía cuerpo en nosotras. Un relato que los alumnos ayudábamos a construir. 
"una mujer que se sube a unos tacos que, entró a un local con balerinas o con zapatillas y se prueba unos tacos, como se siente? Bien pero extremadamente sexy, se para ya distinto con los hombros más para atrás mientras se mira el zapato ya su postura habla desde otro lado; tienen ese poder de darte felicidad de manera inmediata más que cualquier hombre. Perdón, pero es así. El zapato te dispara una felicidad impresionante eh, y también te ayuda a desenvolverte en otro rol, en otro papel"

Comentario de Marcela durante la clase de accesorios

\section{Entrenar la mirada: de Bearne a Recoleta}

"Espero y deseo que la mirada que tengan hacia otra persona haya evolucionado en estos meses de clase porque ya no puede causarte las mismas sensaciones una persona bien vestida o una que no está correctamente vestida”. Así comenzaba la clase de accesorios Marcela, interpelándonos sobre nuestro aprendizaje y cómo éste debía cambiar nuestra forma de "mirar".

El trabajo de Bourdieu me permitió pensar las clases a partir del concepto de habitus y hexis corporal para poder ser consciente y cuestionar ese "algo" más que se transmitía en las clases. Para este autor "el modo en que portamos nuestro cuerpo no depende solamente de sus características biológicas sino de cómo lo vamos domesticando a lo largo de nuestra vida para adecuarlo a las expectativas sociales incorporadas" (Citro, 2010: 182). El baile que describe etnográficamente implicaba una experiencia práctica, un escenario que permitía el encuentro de corporalidades con diferentes trayectorias sociales y modelos culturales, al igual que nos sucedía como alumnas cada martes.

Desde este abordaje es central pensar en el cuerpo,-foco principal de atención, cuidados, recomendaciones, materia a ser moldeada por especialistas en cabello, piel, perfume- de aquellos que durante un año nos acercamos al centro. Un cuerpo que era (re) entrenado y educado en los modos de caminar, sentarse, moverse y por lo tanto sentir. Moldeado y definido por objetos y accesorios que hacían de ese cuerpo un cuerpo elegante, refinado y seguro. Un cuerpo domesticado para un tipo de sociedad, un estilo de vida, de profesión o para un determinado evento.

En algunas clases, los alumnos pasábamos a ser los protagonistas y vivenciábamos esos cambios, como en la clase de maquillaje donde la profesora, mientras explicaba los pasos, maquillaba a las alumnas que querían. En la clase de peinado el profesor, un reconocido peluquero, cortó y peinó a las alumnas, no sin antes detallarnos quiénes eran sus clientas famosas y cuáles le debían su look a él. Fue en esta oportunidad donde me ofrecí para que me peinen y pude ver y sentir en mí un cambio a partir de ser peinada por un peluquero profesional, algo que confirmaba en las expresiones de mis compañeras ante él mismo. Era la primera vez que veía en ellas una mirada de aprobación sobre mí, mirada que algunas pusieron en palabras y me felicitaban por mi cambio alentándome a sostenerlo. Esta experiencia me mostraba que tenía que entender que verse bien significaba un tiempo de preparación, dedicación y gastos en productos de belleza, es decir en todo un conocimiento necesario y una predisposición que sabían yo no poseía. 
Por todo esto, el cuerpo es considerado algo más que ese soporte material de nuestra individualidad, nos representa empíricamente como personas, como sujetos sociales. Marcela, quien enseñaba y guiaba nuestros pasos de baile en este gran salón, sentenciaba en la clase de accesorios "como expertos en imagen necesitamos conocer, luego sacaremos conclusiones de porqué cuestan lo que cuestan determinadas carteras, zapatos (...) aunque yo no pueda acceder o comprar, entiendo qué hay detrás de este mundo". Ya no era necesario acceder a ese objeto, no era necesario poseerlo porque el conocer sus atributos, el ser capaces de poder reconocerlo en otra persona a partir de la información y el conocimiento que nos brindaban en este espacio ya nos posicionaba, nos acercaba a eso que deseamos y en el mejor de los casos vivir la experiencia de probarlo en un negocio, aunque sea en un outlet, de sentir un pañuelo Hermes rozando nuestra piel, de tener esa experiencia sensorial, por muy efímera que sea. Experiencias que se volvían materiales en muchos casos a través del consumo de objetos de imitación, marcas de ropa importantes pero nacionales, como la compra de una cartera Blaqué, o el acceso de productos de marcas internacionales en los outlet de Miami o en épocas de liquidación, como dice Bourdieu (1984), objetos que son capaces de "hacer", como se suele decir, otra cosa que lo que son, maneras todas ellas que tiene lo pequeño de "parecer grande".

Las clases funcionaban como ese detrás de escena para ser capaces de convertir el cuerpo real en un cuerpo legítimo, pero también toda esa información y conocimiento que se adquiría en cada clase nos interpelaba a los alumnos desde el lugar social que ocupamos. Aprendimos también a tener otra mirada.

¿Qué cambiaba a partir de conocer esta "ciudad” en nosotras como alumnas? ¿Qué miradas estábamos interiorizando?

Aprendimos durante el curso a identificar esas marcas sociales, a clasificar. Detrás de este entrenar la mirada había un marco de referencia que permitía poder distinguir e identificar a otra persona a partir de su hexis corporal, esa manera de estar, hablar, caminar, llevar el cuerpo y comportarse, de sentir y de pensar. Al mismo tiempo esas diferencias expresaban una "forma particular de experimentar la posición en ese espacio social mediante la comprobación de la distancia que existía entre el cuerpo real y el cuerpo legítimo" (Bourdieu, 1986:184).

Aprendimos también a ser capaces de identificar el objeto como el lugar que éste representa en el sistema social, no era solamente un par de zapatos de Jimmy Choo, sino que el mismo formaba parte de una trama social. Esto iba unido a un relato de las situaciones que permitían entender el concepto que rodeaba ese objeto. Durante la clase de accesorios Marcela nos contó durante la clase de accesorios que "Rene (Caovilla) siempre decía que sus zapatos son tan maravillosos que son para que un hombre te pase a buscar en limusina por tu casa cosa que no camines, que subas a la limusina que te lleve a un súper restaurante y luego cuando vuelvas con él a tu casa y entre el caballero elegante que te fue a buscar, te saques en la puerta de tu dormitorio los Caovilla y empezar descalza a ser quien sos! ¿Ven el concepto de llevar un Caovilla en los pies?"

En las clases no solo se mostraban imágenes, que iban acompañadas de un discurso tanto de la profesora como de mis compañeras en las que se reafirmaba la calidad, el estilo o la suntuosidad de un objeto. También lo contrario, la sanción por el mal uso o la mala com- 
binación de este, al mismo tiempo que nos mostraban cómo "famosos" representaban "al mal vestido".

A través de los ejemplos negativos que daban los profesores de famosas mal vestidas o famosas que eran, según ellos, "exhibidoras de lujo y no consumidoras" se estaba penalizando la participación, a través del consumo, de un espacio que no le pertenecía, situación que sólo podía revertirse con la intervención de una asesora, conocedora de las reglas del juego vigente y de los modos apropiados de jugar. Estos ejemplos de lo que no debía hacerse servían como base para tomar nuestras propias decisiones como consumidoras al mismo tiempo que funcionaban como una vara para marcar el límite de lo que estaba y no permitido.

Durante las clases nos enseñaban a establecer relaciones a través de una pedagogía que era al mismo tiempo implícita y explícita, eso que no se decía directamente pero estaba presente, como dice Bourdieu, "al colocar el cuerpo en una postura global apropiada para evocar los sentimientos que le están asociados” (Bourdieu, 1980:112). Es decir, íbamos construyendo sentido a partir de la mirada propuesta por el curso.

\section{Conclusión}

Las clases apuntaban a enseñarnos cómo transformar la imagen de un cliente, a ser capaces de observarlo y de analizarlo, definirlo y clasificarlo a partir del modo en el que estaba vestido, de la forma en la que caminaba y hablaba. Por lo tanto, verlo de la manera particular que desde el CD eran definidas la elegancia y el buen gusto. En el presente trabajo intenté mostrar cómo esa mirada, esos nuevos anteojos, que nos enseñaba cómo interpretar a un otro, también lo hacía con nosotros: los alumnos. Esa mirada también se dirigía a nuestros cuerpos, a nuestras elecciones.

Cada uno de los que participábamos del curso estábamos ahí por un motivo distinto. Muchas de mis compañeros lo elegían para poder ser ellos sus propios asesores, para poder aplicar cada recomendación, cada conocimiento nuevo en sus cuerpos y en sus vidas donde este era valorado. Aún aquellos que estudiaban con un fin profesional eran conscientes de que estaban en un espacio social que les exigía no solo manejar esta información sino también aplicarla en sus vidas. Porque en tanto asesores, su imagen era tan importante como las habilidades que les serán requeridas en tanto profesionales. Esto generó cambios en alguno de ellos, como en Nicolás quien también durante la clase de peinados se dejó cortar el pelo con el profesor, a quien le pidió un cambio para mejorar su imagen. $\mathrm{O}$ en el caso de Claudia quien visiblemente cambió su estética a lo largo del curso aplicando las recomendaciones de los diferentes profesores, desde las telas para confeccionar sus pantalones hasta el corte de pelo que más la favorecía. Cambios que todas notábamos y celebrábamos. Me inscribí en el curso con la intención de conocer el espacio y aprender de él como investigadora. Pero desde que ingresé al centro me di cuenta que era diferente al resto de mis compañeras. No sólo por la forma de vestirme y peinarme sino también en cómo me movía y hablaba, es decir en mi hexis corporal. Como le sucedía al campesino, su distancia cultural con los jóvenes de la ciudad no era solamente debido a su vestimenta sino también esa distancia estaba presente en sus modos y técnicas corporales. Pero con 
el paso de los meses me di cuenta que el estar ahí, el escuchar a los profesores y aplicar sus recomendaciones, el conversar con mis compañeros, el verlos cada semana, generaron y motivaron cambios en mí. De pronto me encontré comprando productos de limpieza facial, observando con atención la indumentaria de otras personas tratando de reconocer e identificar su estilo, entre otras cosas. Mi mirada no era la misma, como la campesina de Bearne quien había cambiado la forma de mirar el habitus del campesino, yo también había adoptado una nueva mirada y modos corporales.

Este espacio podía pensarse como las vidrieras que recorrían las campesinas en la ciudad: conocíamos solo el aspecto del tema y desde la perspectiva que elegía el profesor y guiaba el centro. Pero no conocíamos cómo y por qué esa vidriera estaba dispuesta y organizada de esa forma ni qué había detrás. ¿Por qué una mujer con zapatos altos se siente "extremadamente sexy"? ¿Por qué al igual que las campesinas queremos aprender a peinarnos y vestirnos "como ciudadanas"? El texto de Bourdieu aclaró aspectos de mi trabajo de campo que me permitieron ver en las clases ese algo más que estaba pasando en mi doble rol de alumna e investigadora y poder analizar "ese saber corporal que se produce en el trabajo de campo" (Citro, 2010:182).

Cada martes el centro se transformaba en un salón donde se impartía un conocimiento que nos interpelaba, donde el cuerpo era el foco principal de atención y materia a ser moldeada. Aprendimos que el "lujo duele y cuesta", que era necesario, para llegar a ese ideal de belleza y elegancia a ese cuerpo legítimo, una inversión de tiempo y dinero. Un lugar de encuentro, de experiencia práctica entre profesores y alumnos donde se reforzaban y actualizaban creencias y representaciones. Donde cobraba forma y contenido esa "ciudad", ese "París" que cada una iba construyendo, representada por los ideales estéticos de consumo y estilos de vida.

\section{Notas}

1. La lectura de los trabajos de Pierre Bourdieu, en especial el "Baile de los solteros", estuvo atravesada, guiada y problematiza a partir de mi lectura del trabajo de Juan Dukuen, Los usos del habitus en la génesis de las investigaciones antropológicas de Bourdieu (19621964). Contribución a un debate, en Prácticas de oficio, n 16, diciembre de 2015. Este texto me permitió comprender y ahondar los principales conceptos teóricos de Pierre Bourdieu.

\section{Bibliografía}

Bourdieu, P. (2010). La distinción. Criterio y bases sociales del gusto (1979), Buenos Aires, Taurus.

. (2010). El sentido práctico (1980), Buenos Aires, Siglo XXI Editores.

. (1986). “Notas provisionales sobre la percepción social del cuerpo", en J.Varela

Álvarez (com.), Materiales de sociología crítica, Madrid, La Piqueta: 183-194.

. (2004). El baile de los solteros. La crisis de la sociedad campesina en el Bearne,

Barcelona, Editorial Anagrama. 
Citro, S. (coord.) (2010). Cuerpos Plurales. Antropología de y desde los cuerpos, Buenos Aires, Editorial Biblos Culturalia.

Gutierrez, A. (2005). Las prácticas sociales: una introducción a Pierre Bourdieu, Ferreyra Editor, Córdoba.

\begin{abstract}
In this article I study from the perspective of Pierre Bourdieu's work “The peasants and their body", my participation as a student in a course of Public and Private Image. From the concepts of Habitus and corporal Hexis I analyze the knowledge that is transmitted in the course not only as specialized information on the subject but as it transforms us, the students. First of all I describe Bourdieu's work, my experience as a student in the center, the course and my classmates. Then I focus on describing the classes and their dynamics. Finally, I explain, from the concepts of Bourdieu, how and why classes can be thought of as a space where, in addition to providing information, new aspirations and desires are built. Where they teach us to look at another, but not in any way but one that is in solidarity with a social and cultural context where that look makes sense.
\end{abstract}

Keywords: Habitus - corporal Hexis - image consulting - person.

Resumo: Neste artigo estudo da perspectiva do trabalho de Pierre Bourdieu "Os camponeses e seu corpo", minha participação como estudante em um curso de Imagem Pública e Privada. A partir dos conceitos de Habitus e Hexis corporal analiso o conhecimento que é transmitido no curso não apenas como informação especializada sobre o assunto, mas como ele nos transforma, os alunos. Antes de tudo, descrevo o trabalho de Bourdieu, minha experiência como estudante no centro, o curso e meus colegas. Então eu me concentro em descrever as classes e suas dinâmicas. Por fim, explico, a partir dos conceitos de Bourdieu, como e por que as classes podem ser pensadas como um espaço onde, além de fornecer informações, novas aspirações e desejos são construídos. Onde nos ensinam a olhar para outro, mas não de maneira alguma, a não ser um que seja solidário com um contexto social e cultural em que esse olhar faça sentido.

Palavras chave: Habitus - Hexis corporal - assessoria da imagem - pessoa.

[Las traducciones de los abstracts fueron supervisadas por el autor de cada artículo] 